\title{
Assessment of Diversity, Population and Related Threats to Vultures in Hadoti Region of Rajasthan
}

\author{
Shubham Suthar, Anchal Sharma, P. S. Chauhan, Kanica Chauhan, \\ Bhuvnesh Nagar* and I. B. Maurya
}

Department of Wildlife Management, College of Horticulture and

Forestry, Jhalawar (Raj.), India

*Corresponding author

\begin{abstract}
A B S T R A C T
In India vultures are ecologically, socially and culturally significant as scavenger. Nine species of vultures are recorded in the Indian subcontinent; seven out of them can be seen in Rajasthan including resident and migratory species. Present study was carried out at eight different study sites in Hadoti Region of south eastern Rajasthan. Total three species of vulture, with total population of 164 individuals were observed during study period using head count method. Among these Long- billed Vulture were highest $(\mathrm{n}=83)$ followed by White-rumped Vulture $(n=69)$ while Egyptian Vulture was minimum population $(\mathrm{n}=12)$. The present study has revealed that the habitat loss, dependency on city carcass, electrocution by the power lines passing through different habitats, human behaviour were the main threats to the species in this area. Out of 40 respondents, $57.5 \%$ had a positive attitude, $22.5 \%$ had a negative attitude and $20 \%$ had a neutral attitude towards vulture.
\end{abstract}

\begin{tabular}{|l|}
\hline Keyw or d s \\
$\begin{array}{l}\text { Vultures, Diversity, } \\
\text { Hadoti Region }\end{array}$ \\
\hline Article Info \\
\hline $\begin{array}{l}\text { Accepted: } \\
\text { 12 November } 2020 \\
\text { Available Online: } \\
\text { 10 December } 2020\end{array}$ \\
\hline
\end{tabular}

\section{Introduction}

Birds are one of the beautiful creatures of our natural heritage and an important part of our cultural past from the antiquity until recently. A vulture is a scavenging bird of prey. All vulture species belongs to the family Accipitridae.

Vultures may not be the prettiest of birds and they often reviled for their looks, but they do the dirty work cleaning up after death, helping to keep the ecosystem healthy and prevent the spread of diseases.
Nine species of vulture can be found living in India, but most are now in danger of extinction after a rapid and major population collapse in recent decades. As recently as the 1980 s there were up to 80 million White rumped vultures (Gyps bengalensis) in India, but today the population numbers only several thousand (IUCN, 2015). Out of these nine species, seven species of vulture found in Rajasthan, Long billed vulture (Gyps indicus), White-backed vulture (Gyps bengalensis), Red-headed vulture (Sarcogyps calvus) and Egyptian vulture (Neophron percnopterus) as breeding residents, Himalayan griffon (Gyps 
hymalayensis), Eurdasian griffon (Gyps fulvus) and Cinereous vulture (Aegypius monachus) are winter migratory species. Vultures perform a vital role, from the ecological point of view vulture are the key components of ecosystem because of their function of cleaning the dead carcasses and provide healthy environment for other living beings on the earth. Their existence is essential for healthy environment. As per different study reports, in the recent past the population of vulture has been declining which was found to be linked with veterinary use of Diclofenac (DF), a Non-steroidal AntiInflammatory Drug (NSAID).

\section{Materials and Methods}

\section{Study Area}

The above study was conducted in Hadhoti region. Hadhoti is a region which lies in western part of Rajasthan, India. It was once called the Bundi Kingdom of western Rajasthan from where data was collected at eight different selected study sites such as Gapernath Temple, Deeppura Village, Harigarh (Chalte forest), Thamlav Village, Borabas Village, Sentab Colony, Near Bhainsroadgarh, Submersible Bridge

Regular and extensive field survey was conducted at selected study sites from July 2019- March 2020 by Line Transect method (Prakash et al., 2012). Survey was done from early morning to sundown period; survey was done at one site per week. All the roosting and nesting vultures were monitored in the morning hours i.e. 07:00 AM to 10:30 AM, this is the time when they come from their nests for basking under the sunlight and fly in the sky over their nests then they go for searching the food and in the evening hours i.e. 04:00 PM to 06:30 PM, this is the time when they return to their nest and fly in the sky around their nests.
Data sheet were prepared and filled during each survey (Figure 1). Vulture's photographs were taken in the field and they were later on identified based on pictures provided in the guide book (Ali and Ripley, 1987; Kazmierczak, 2000).

Population status was studied through Head count method (Kumar et al., 2014; Chhanjani, 2007; Purohit and Saran, 2013). Head count method: The population status of different species of vulture was studied by means of the head counting method, supported by photography and video recordings. During study period GPS location of nesting, roosting and feeding sites was recorded; photographs were captured to identify vulture species perfectly; head count through binoculars to estimate individuals and had been done. Observation was made from safe distance ranging 300 to $600 \mathrm{~m}$ from the cliffs with the aid of Binocular (Purohit and Saran, 2013).

\section{Results and Discussion}

\section{Population and Distribution}

Out of the seven species of the vulture in Rajasthan, three vulture species were sighted during the study period include White-rumped vulture, Egyptian vulture and Long billed Vulture

A total of 164 (Fig. 2-5) vultures of three species WBV (White-rumped Vulture), LBV (Long-Billed Vulture) \& EV (Egyptian Vulture) were observed. Among them highest number of individuals ( $\mathrm{n}=83$ ) were of Long billed vulture (Fig. 2), followed by Whiterumped vulture $(n=69)$ (Fig. 3), while least population was of Egyptian vultures $(n=12)$ (Fig. 4) was observed. A maximum of Vultures ( $n=45$ were recorded at study site VII, while minimum of vultures $(n=11)$ were recorded at study site II. The average flock size of vultures recorded was 20.5 with 
Standard Deviation (S.D.) 3.86 (Table 1). NPCIL (2010) recorded the average flock size of vultures near Rawatbhatta Rajasthan was 34.83 with Standard deviation (S.D.) 20.45 and the average flock size of White-rumped vultures recorded were 19.16 with S.D. 16.92 .

During the study it was observed that, the number of vultures found varied by sites, the highest number of vultures found was in Submersible Bridge i.e. study site VII, while the lowest number found was in Deeppura Village i.e. study site II (Fig. 1). The average flock size of Long-billed vulture was recorded 10.37 with standard deviation 3.90. The number of individuals of Long-billed vulture was maximum at study site VII and was found to be minimum at study site II and III. (NPCIL 2010) recorded the average flock size of Long-billed vultures recorded were 11.5 with S.D. 7.13. The average flock size of Egyptian vulture was recorded 1.5 with standard deviation 1.58. The number of individuals of Egyptian vulture was maximum at study site VI and was not found at study site I, V, VII and VIII. (NPCIL 2010) recorded the average flock size of Egyptian vultures recorded were 4.16 with S.D. 2.26.

Their local status has been given according to their survey conducted at the selected study sites as well as according to Wildlife Protection Act - 1972 has been given, according to which all the species that were recorded at the selected study sites during the study period are highly protected under Schedule -I of Wildlife Protection Act -1972 (Table 2).

Table.1 Showing flock size of vulture at all study sites

\begin{tabular}{|c|c|c|c|c|c|c|c|}
\hline \multirow{2}{*}{$\begin{array}{c}\text { Study } \\
\text { Site }\end{array}$} & \multirow[t]{2}{*}{ Name of site } & \multirow{2}{*}{$\begin{array}{c}\text { No. of } \\
\text { vultures } \\
\text { observed }\end{array}$} & \multicolumn{3}{|c|}{ Species of vulture } & \multirow{2}{*}{$\begin{array}{l}\text { Average } \\
\text { flock size }\end{array}$} & \multirow{2}{*}{$\begin{array}{l}\text { Standard } \\
\text { Deviation } \\
\text { (S.D.) }\end{array}$} \\
\hline & & & WRV & LBV & EV & & \\
\hline I & Gapernath Temple & 16 & 3 & 13 & 0 & \multirow{8}{*}{20.5} & \multirow{8}{*}{3.86} \\
\hline II & Deeppura Village & 11 & 3 & 6 & 2 & & \\
\hline III & Thamlav Village & 12 & 3 & 6 & 3 & & \\
\hline IV & Borabas Village & 14 & 4 & 7 & 3 & & \\
\hline $\mathbf{V}$ & Sentab Colony & 25 & 15 & 10 & 0 & & \\
\hline VI & Near Bhainsroadgarh & 28 & 14 & 10 & 4 & & \\
\hline VII & Submersible Bridge & 45 & 27 & 18 & 0 & & \\
\hline \multirow[t]{2}{*}{ VIII } & Harigarh (Chalte forest) & 13 & 0 & 13 & 0 & & \\
\hline & Total & 164 & 69 & 83 & 12 & & \\
\hline
\end{tabular}

Table.2 List of Vulture species along with their status according to WPA- 1972

\begin{tabular}{|c|l|l|}
\hline S. No. & Vulture species & WPA-1972 Status \\
\hline $\mathbf{1}$ & White-rumped vulture & Schedule I \\
\hline $\mathbf{2}$ & Long-billed vulture & Schedule I \\
\hline $\mathbf{3}$ & Egyptian vulture & Schedule I \\
\hline
\end{tabular}


Table.3 Showing threats observed during study

\begin{tabular}{|l|l|l|}
\hline Study site & Threats & Remarks \\
\hline Gapernath Temple & Tourism & Human encroachment \\
\hline Deeppura Village & Conflict & Feral dogs attack \\
\hline Thamlav Village & Electrocution & High risk in damping area \\
\hline Borabas Village & Habitat loss & Human encroachment \\
\hline Sentab Colony & Habitat loss & Natural Disaster \\
\hline Near Bhainsroadgarh & Tourism & Human encroachment \\
\hline Submersible Bridge & Low availability of Food & No Dumping site near colony \\
\hline Harigarh & Low availability of Food & No Dumping site near colony \\
\hline
\end{tabular}

Fig.1 Graph showing population of different species of vulture at different study sites

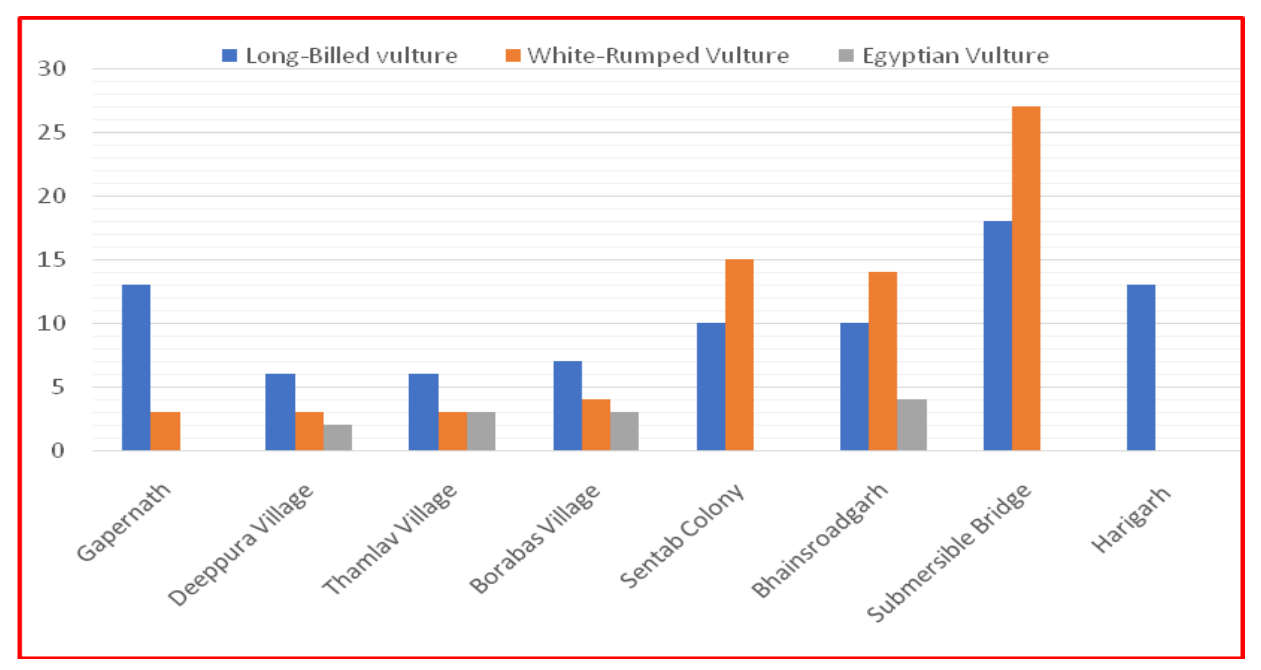

Fig.2 Showing flock of long-billed vulture

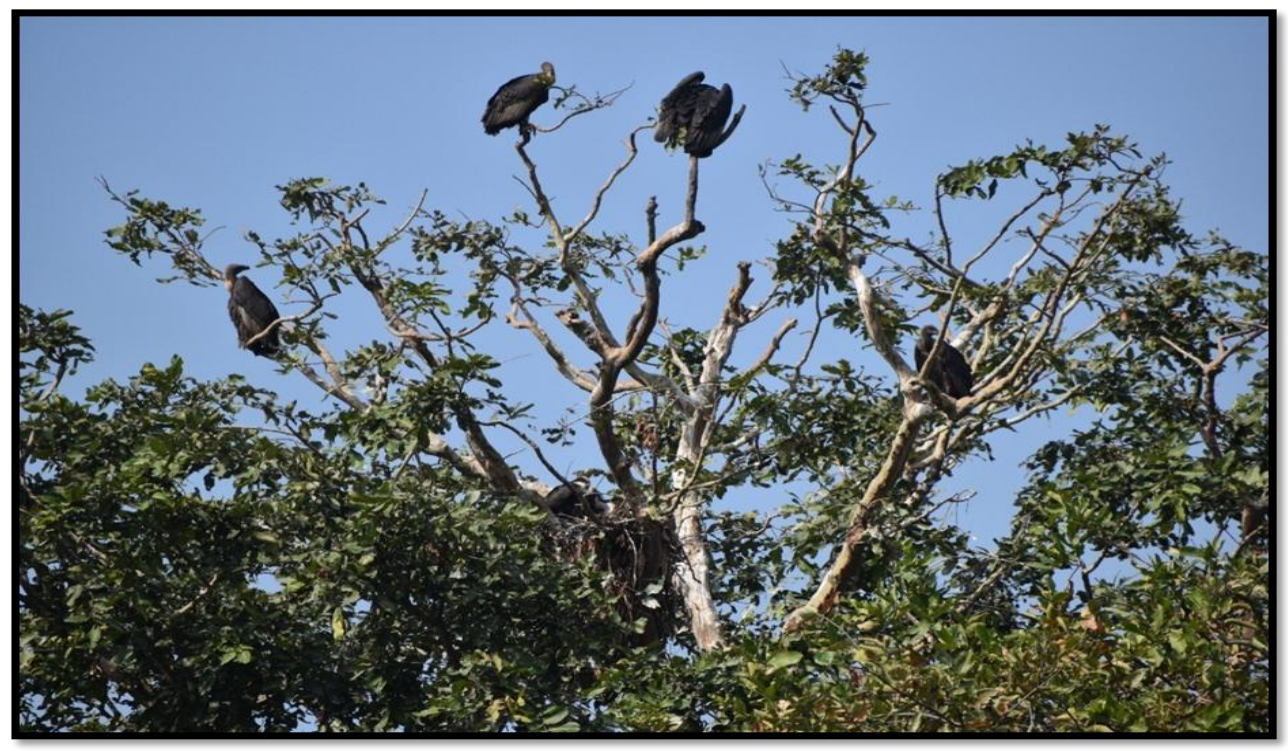


Fig.3 Showing white rumped vulture

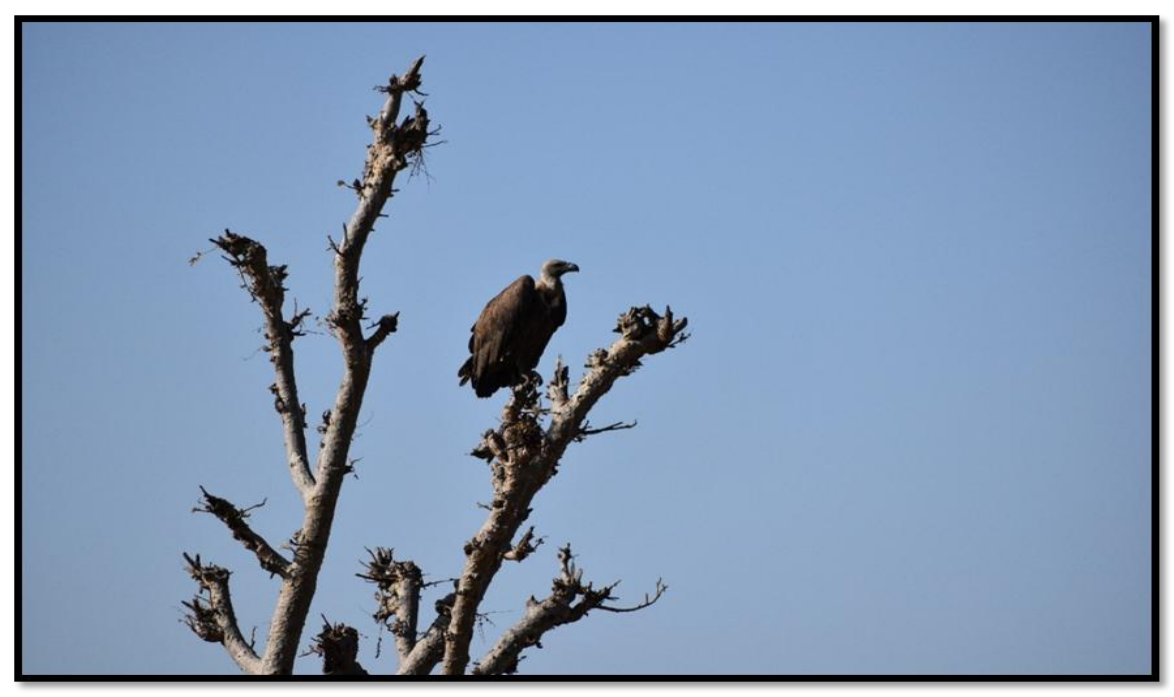

Fig.4 Showing Egyptian vultures
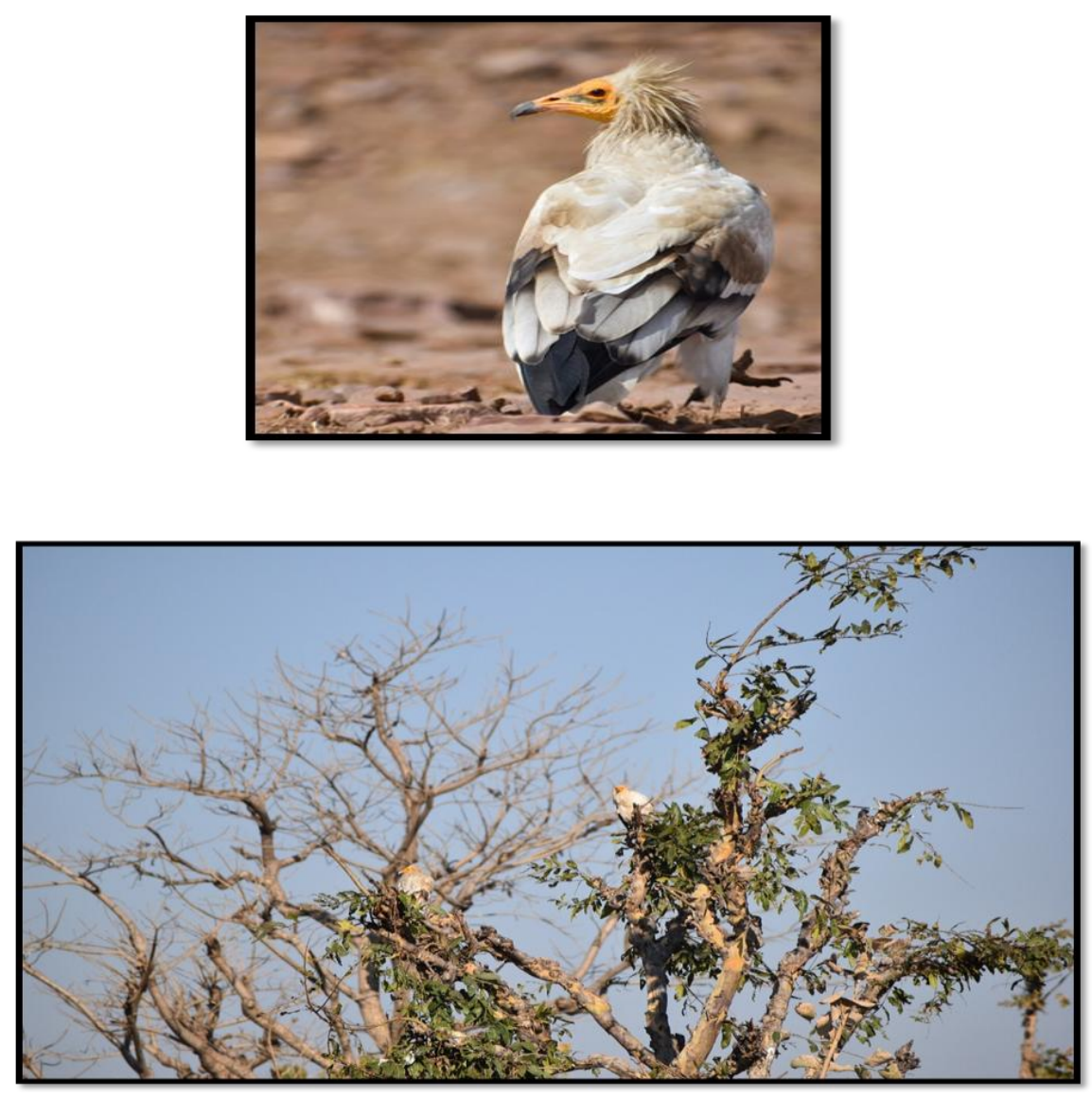
Fig.5 Showing Long-billed vulture (juvenile) and White-rumped vulture (juvenile)
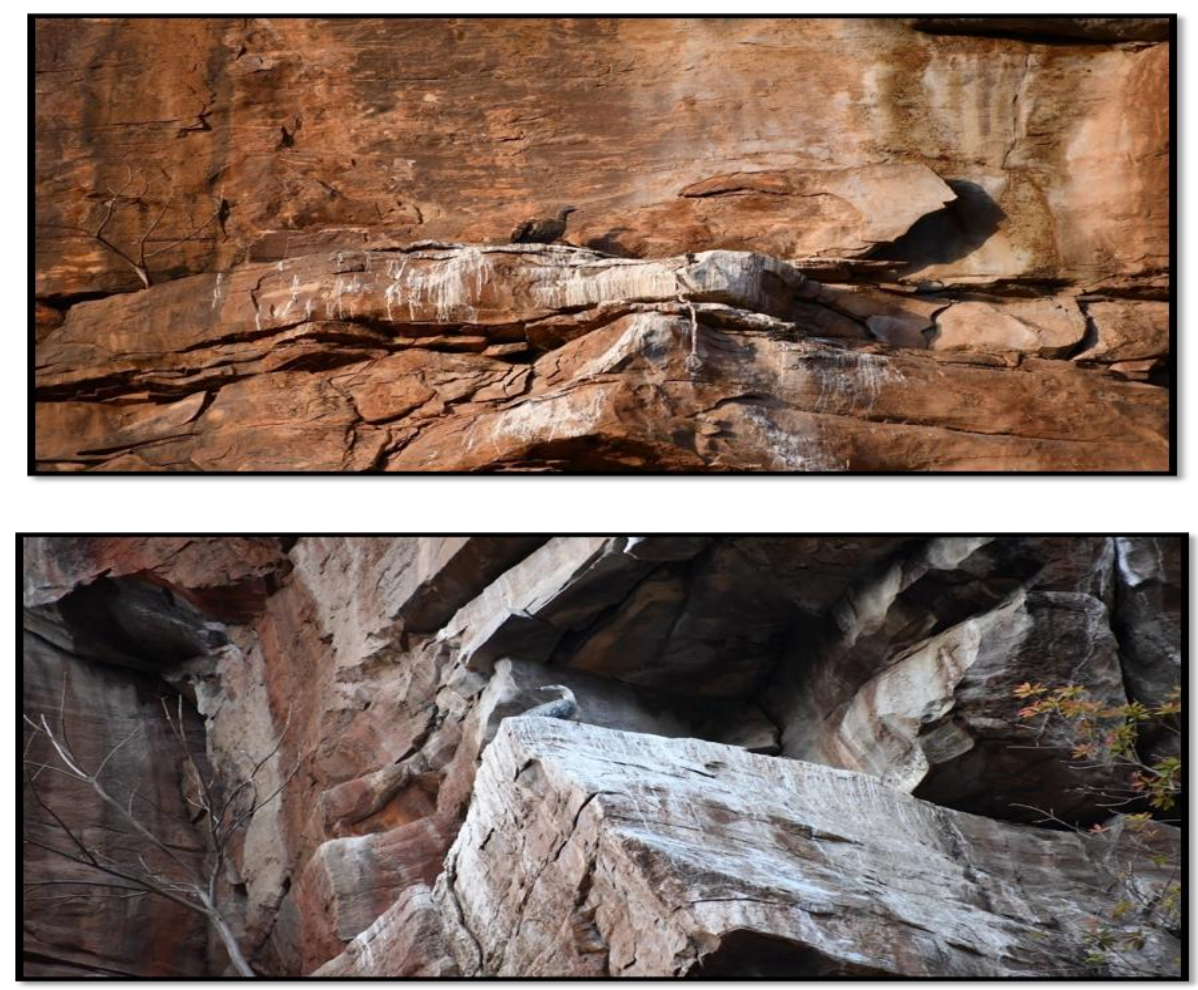

\section{Threats observed during the study}

On the basis of observation taken during study and also through the interview conducted with the local people residing in the study site area following threats were observed to the population of vultures (Table $3)$.

Electrocution: - 2 dead vulture reported dead by local people at electric pole, near the dumping ground of Gapernath.

Feral dogs: Attack by street dogs was observed by the local people at dumping site during the feeding.

Veterinary drug: $86 \%$ of respondents use veterinary drug to treat their livestock, and this drug causing a threat to vulture since they will feed on that livestock later on.

Habitat loss: From the interview it was also came into notice that, Due to human encroachment, vultures lost many of the roosting sites.

Tourism: It is creating disturbance to the population of vulture, due to which they are forced to leave their roosting place and shift to some other habitat.

Lack of dumping places: At some sites, dumping places are far away due to which vultures cannot reach to the carcass timely and when they reach by the time carcass was already finned by feral dogs and other birds.

Out of 40 respondents, $57.5 \%$ had a positive attitude, $22.5 \%$ had a negative attitude and $20 \%$ had a neutral attitude towards vultures. Only 29 respondents had observed vultures in their area; of them, $55.17 \%$ had noticed vulture declines. Out of 40 respondents, $86 \%$ consult a veterinarian while $11 \%$ use traditional veterinary medicine and remaining other do not consult a veterinarian before the treatment of their livestock. 
Study found that the neutral attitudes have occupied a significant proportion (20\% towards vultures and $15.8 \%$ towards vulture conservation). The sudden decline of vultures during 1990s and their disappearance may have increased the unfamiliarity with a number of people and may have created the neutral attitude towards vultures. Weaker attitudes towards vulture and its conservation can become a barrier to successful conservation programmes as people with neutral (or weaker) attitudes are less likely to care about the species or be indifferent to change their attitudes, as in the case of the wolf in Sweden (Ericsson and Heberlain, 2003).

If we do not consider the neutral attitude, it can turn to negative attitude due to the unattractiveness and carcass eating behaviour of the vultures.

Providing information about status and importance of vultures can gather support for conservation programmes as accurate information is helpful to transform into positive attitude towards the species and promote local support for the conservation (Baral et al., 2007; Barnes 2013; Ghimire et al., 2014).

With high proportion of people in favour of vulture conservation, the Egyptian Vulture populations might have a lower probability of intentional persecution. The carcass burying activity seems particularly unfavourable for vulture's survival.

Recommendations: Following measure need to adopt for the better conservation of the species:

Awareness among people

Habitat Management

Regular Monitoring

Enforcement of Wildlife Protection Act 1972
Vulture restaurants: More dumping outside the city areas where diclofenac free carcass are regularly provided to vultures should be maintained wherever and whenever required.

It was concluded from the study that total 164 individuals of 3 different species were found at all 8 different study sites during the study period. Among the total population the individual Indian Vulture (Gyps indicus) were 69, Egyptian vultures (Neophron percnopterus) were 12 and white-rumped (Gyps bengalensis) vultures were 83. The average flock size of vultures was recorded to be 20.5 with Standard Deviation (S.D.) 3.86. Ethogram data shows that they spend maximum time in foraging, followed by resting.

Out of 40 respondents, $57.5 \%$ had a positive attitude, $22.5 \%$ had a negative attitude and $20 \%$ had a neutral attitude towards vultures. Only 29 respondents had observed vultures in their area; of them, $55.17 \%$ had noticed vulture declines. Out of 40 respondents, $86 \%$ consult a veterinarian while $11 \%$ use traditional veterinary medicine and remaining other do not consult a veterinarian before the treatment of their livestock.

This study suggests that people with neutral attitudes towards vulture is significant. It was clearly seen from the study that this species plays an important role in ecosystem by keeping the ecosystem healthy and preventing it from spread of diseases. Vultures are facing major threats as we have seen during the study so it suggested conserving these important species by making people aware about their importance. Fast disappearance of vultures in India is a matter of serious concern and needs immediate attention of the government to conserve these scavenger birds so that the environment can be keep neat and clean to avoid the rabies-related deaths. 


\section{Acknowledgement}

The author is highly great full to the college of horticulture and Forestry, Jhalawar (Agriculture University, Kota) for support during the course of study.

\section{References}

Ali, S. and Ripley, R. (1987). Compact handbook of the birds of India and Pakistan, Oxford University press, Delhi, 296-314.

Barnes, P. (2013). Battitude: an assessment of human attitude and behaviour towards the critically endangered Pteropus rodricensis. MSc Thesis. Department of Life Sciences, Imperial College, London, the UK.

Chhangani, A. K. (2007). Sightings and nesting sites of Red-headed Vulture (Sarcogyps calvus) in Rajasthan, India. Indian Birds, 3(6): 218-221.

Ericsson, G. and Heberlein T. A. (2003). Attitudes of hunters, locals, and the general public in Sweden now that the wolves are back. Biological conservation 111(2): 149-159.

Ghimire, H.R., S. Phuyal and K.B. Shah (2014). Protected species outside the protected areas: people's attitude, threats and conservation of the Yellow Monitor (Varanus flavescens) in the far-western lowlands of Nepal. Journal for Nature Conservation 22(6): 497-503.

IUCN. (2015). Archived from the original on June 27, 2014.

Kazmierczak, K. (2000). A Field Guide to the Birds of the Indian Subcontinent,
London: Pica Press / Christopher Helm, p. 356.

Kumar, S., Meena, H., Jangid, P. K. and Nara, K. S. (2014). Current Status of Vulture population in Chambal Valley of Kota, Rajasthan. International Journal of Pure \& Applied Bioscience, 2(5): 224-228.

Lopez, B.M., C. Montes and J. Benayas (2007). The non-economic motives behind the willingness to pay for biodiversity conservation. Biological Conservation, 139(1): 67-82.

NPCIL ( 2010) A report on study of vultures (Endangered species) around Rawatbhata Rajasthan site. An initiative of Rawatbhata Rajasthan sites as part of environment stewardship programme, NPCIL, India.

Prakash, V. (1999). Status of vultures in Keoladeo National Park, Bharatpur, Rajasthan, withspecial reference to population crash in Gyps species. Journal of the Bombay Natural History Society, 96(3): 365-378.

Prakash, V., Bishwakarma, M. C., Chaudhary, A., Culthbert, R. and Dave, R. (2012). The population decline of Gyps vulture in India and Nepal has slowed since Veterinary use of Diclofenac was banned. Plos One, 7(11): e49118.

Purohit, A. and Saran, R. (2013). Population Status and Feeding Behaviour of Cinereous Vulture (Aegypus monachus): Dynamics and Implication for the species Conservation in and around Jodhpur. World Journal of Zoology, 8(3): 312-318.

\section{How to cite this article:}

Shubham Suthar, Anchal Sharma, P. S. Chauhan, Kanica Chauhan, Bhuvnesh Nagar and Maurya, I. B. 2020. Assessment of Diversity, Population and Related Threats to Vultures in Hadoti Region of Rajasthan. Int.J.Curr.Microbiol.App.Sci. 9(12): 1302-1309.

doi: https://doi.org/10.20546/ijcmas.2020.912.160 